\title{
Precipitating hydrophobic injectable liquid (PHIL) embolic for the treatment of a uterine arteriovenous malformation: a technical report
}

\author{
Dylan Kurda ${ }^{1 *}$ (D) Geetha Guduguntla ${ }^{1}$, Julian Maingard ${ }^{2,3}$, Hong Kuan Kok ${ }^{4,3}$ and Shivendra Lalloo ${ }^{1}$
}

\begin{abstract}
Objective: Uterine arteriovenous malformations (AVM) are unusual causes of vaginal bleeding. Although hysterectomy is the definitive treatment; uterine artery embolization (UAE) provides an alternative therapeutic option. This case presents a technical report of a uterine AVM treated successfully with transcatheter UAE using precipitating hydrophobic injectable liquid (PHIL) embolic agent.

Case report: A 41-year-old female, gravida 6, para 4, miscarriage 2, including a molar pregnancy 15 years prior, presented with massive per vaginal bleeding. Pelvic ultrasound demonstrated an acquired AVM as the underlying aetiology for her presentation. The patient underwent bilateral uterine arterial embolization. Four weeks later, there was nearly complete resolution of the AVM and the patient's menstrual cycle was restored 8 weeks after the procedure.
\end{abstract}

Conclusion: Uterine AVM can be treated safely and effectively with UAE using PHIL.

Keywords: Embolization, PHIL, Uterine artery, AVM

\section{Introduction}

Uterine arteriovenous malformation (AVM) is a rare cause of menorrhagia that may cause life threatening bleeding. The diagnosis is most commonly established by pelvic ultrasound although other cross-sectional imaging modalities including CT and MRI are also helpful. Uterine artery embolization (UAE) is one of the therapeutic options, for which several embolic agents have been mentioned in literature. The first successful transarterial embolization for uncontrolled uterine bleeding from fibroids was performed in 1974 by Jean-Jaques Merland (Yoon et al., 2016; Sellers et al., 2013) and UAE is now an established first-line treatment option for symptomatic fibroids.

Although there is more limited experience with UAE for treatment of uterine AVM, the choice of technique and embolic agent can impact on the success of

\footnotetext{
* Correspondence: Dylan.kurda@gmail.com

${ }^{1}$ Interventional Radiology, The Canberra Hospital, Canberra, Australia Full list of author information is available at the end of the article
}

endovascular embolization with varying rates of primary occlusion and recurrence reported in the literature ${ }^{1}$. We report our preliminary experience using a novel liquid embolic agent, precipitating hydrophobic injectable liquid (PHIL; MicroVention, Tustin, CA) demonstrating safety and efficacy for the treatment of a large post-partum uterine AVM.

\section{Materials and methods}

A 41-year-old gravida 6, para 4 (G6P4) was referred to our institution following large volume per vaginal (PV) bleeding with an estimated $900 \mathrm{ml}$ blood loss. Her past history was significant for two miscarriages, one resultant from a molar pregnancy 15 years prior. She last gave birth to a normal term baby 4 months prior to this presentation; which was a normal vaginal delivery. Her immediate postpartum course was uneventful, without complications such as sepsis and retained product of conception. She was on a regular dose of the combined oral contraceptive pill. 
Upon this presentation, she was initially treated with 2 units of packed red cells, tranexamic acid, norethisterone and naproxen but her symptoms failed to respond to medical therapy. Duplex pelvic ultrasound demonstrated an anteverted uterus with changes of adenomyosis and a left cornual AVM measuring $4 \times 3 \times 3 \mathrm{~cm}$ in the anterior myometrium (Fig. 1a and b). She was referred for transcatheter UAE to treat the underlying AVM.

\section{Procedure details}

Following informed consent and under conscious sedation, retrograde right common femoral artery access was obtained followed by placement of a 6-French introducer sheath (Cook, Bloomington, IN). The left and right internal iliac arteries were selectively catheterised using a 5-French $\mathrm{C} 2$ catheter (Glidecath, Terumo) and hydrophilic guidewire combination (Glidewire, Terumo). Selective angiography of the internal iliac artery demonstrated an anterior left paramedian uterine AVM nidus supplied by both uterine arteries and an associated post-nidal varix. We used 5000 units of intraarterial unfractionated heparin (we normally do use heparin in such situations due to potential lengthy procedures and the use of long sheaths / guide catheters). Distal catheterization of the markedly tortuous uterine arteries was performed using a dual lumen Scepter XC balloon microcatheter and Traxcess wire combination (Microvention) delivered through a 6 Fr guide sheath (Destination,Terumo) for proximal support. Pulsed injection of $7 \mathrm{ml}$ of $25 \%$ and $2 \mathrm{ml}$ of $30 \%$ PHIL liquid embolic (to bilateral uterine arteries) achieved satisfactory nidal penetration, with post embolization aorto-iliac angiography suggesting no further early venous filling. Despite the lack of post-nidal venous penetration which may allow recurrent shunting, adequate devascularization was achieved (Fig. 2 a-e). Access site hemostasis was achieved with a vascular closure device (AngioSeal, Terumo).

\section{Results}

The patient recovered well; her PV bleeding tapered off over a 10-day period and subsequently ceased. Follow-up pelvic ultrasound demonstrated obliteration of the nidus with no residual vascularity within the region of the original AVM (Fig. 3). She restarted her oral contraceptive pill post-embolisation. Her post-embolisation course was uneventful apart from mild pelvic pain in the first few days post procedure which was adequately managed with oral analgesics. There was no clinical evidence of post embolization syndrome. The patient remained well at 5 month follow-up and was asymptomatic.

\section{Discussion}

Uterine AVMs are rare, and their true incidence is not clear. They are believed to be underestimated as they are often clinically silent prior to late presentation with severe PV haemorrhage (Sellers et al., 2013). Approximately $50 \%$ of uterine AVMs are congenital and thought to be the result of failure of embryonic capillary plexus differentiation (Kasznica \& Nisar, 1995). The remainder of AVMs are acquired after miscarriage, uterine instrumentation, Caesarean section or other uterine surgery, or related to neoplastic disorders like gestational

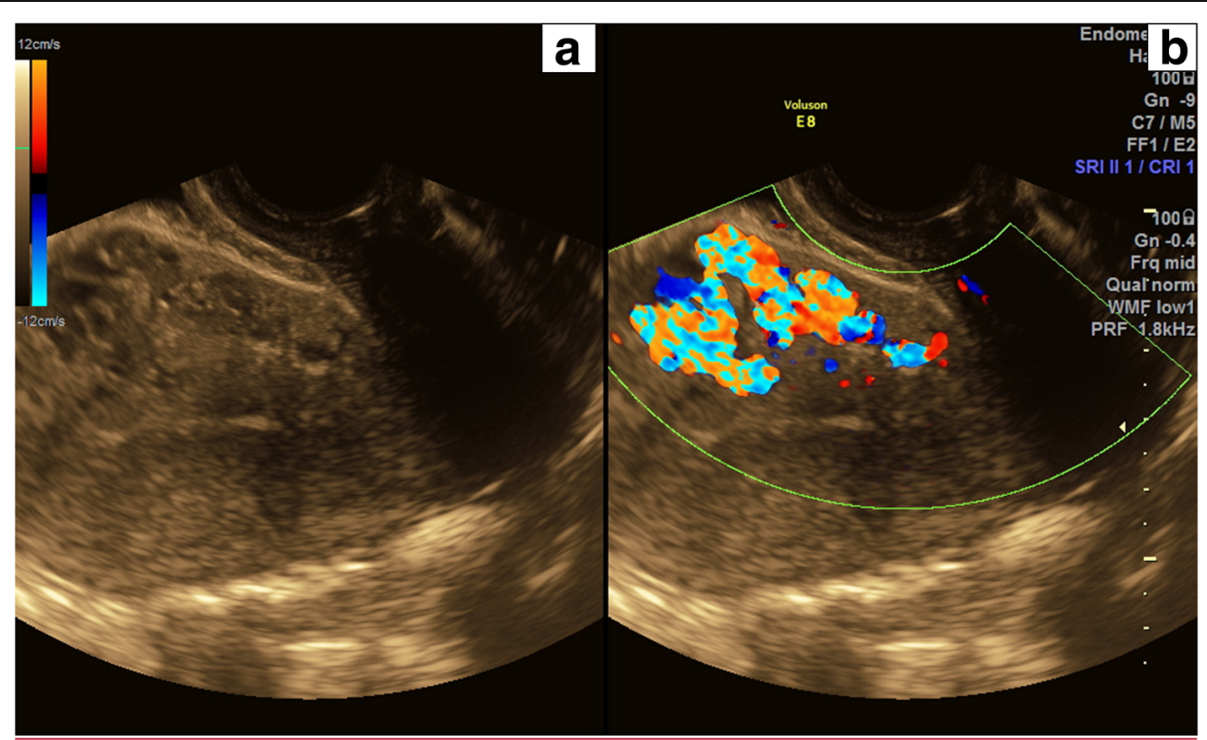

Fig. 1 a Sagittal transvaginal pelvic ultrasound image demonstrating a serpinginous hypoechoic area in the anterior myometrium compatible with an anterior cornual AVM. b Colour Doppler overlay demonstrating markedly increased high-flow vascularity of the AVM 

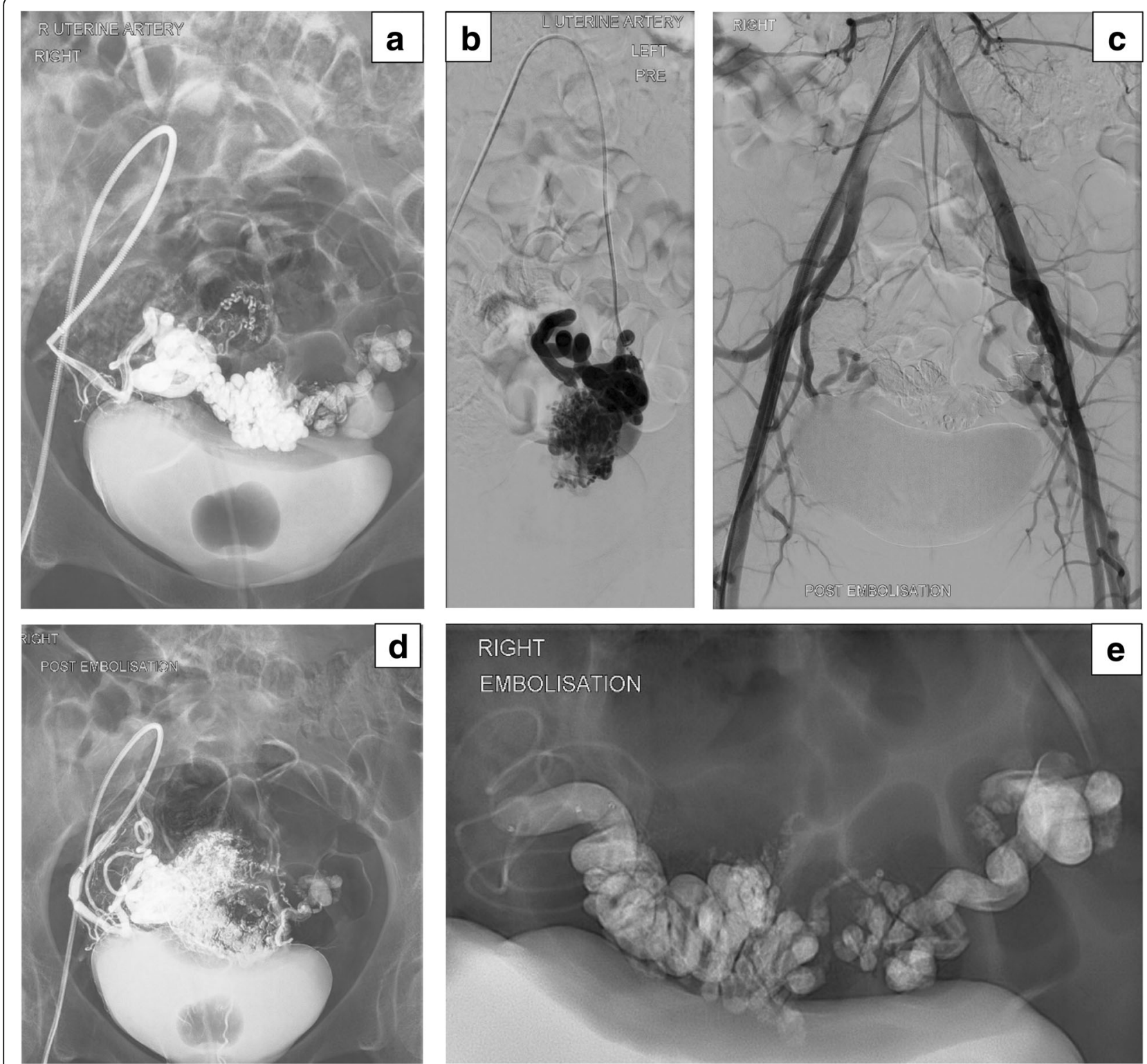

Fig. 2 a-e. 41-year-old female with symptomatic acquired uterine AVM. a Right uterine artery demonstrates hypertrophied right uterine artery and AV shunting, with draining venous varix; $\mathbf{b}$ Left uterine artery with evidence of AV shunting and a well demonstrated nidus; $\mathbf{c}$ Aortogram post bilateral UAE, showing obliteration of the AV shunting and no further feeder from internal and / or external iliac arteries; d Post right uterine artery embolisation with PHIL, showing no evidence of AV shunting. Adequate nidus penetration with the embolic cast also seen; e Post bilateral UAE demonstrating PHIL cast and the Scepter XC catheter. It also nicely demonstrates the marked tortuosity of the hypertrophied right UA

trophoblastic disease and endometrial adenocarcinoma. Maternal diethylstilboestrol (DES) use has also been implicated.

In the puerperium, there is a recognized continuum from self-limiting subinvolution of retained placental vasculature to persistent pathologic shunts which present as symptomatic acquired AVMs (Sellers et al., 2013). First-line imaging includes assessment with pelvic duplex ultrasound; although, cross sectional imaging can help to characterise the exact nature and relationship to surrounding structures including the number and location arterial in-feeders, location and size of the nidus as well as the presence of venous varices and flow related aneurysms (Timor-Tritsch et al., 2016; Kwon \& Kim, 2002). Cross sectional imaging has the added benefit of allowing accurate characterisation of residual nidus following treatment.

Management of uterine AVMs is dictated by the clinical status and age of the patient, site and size of the AVM, and the desire for gestation in the future (Molvi et al., 2011). Percutaneous transarterial embolization has become established as an effective treatment for uterine 


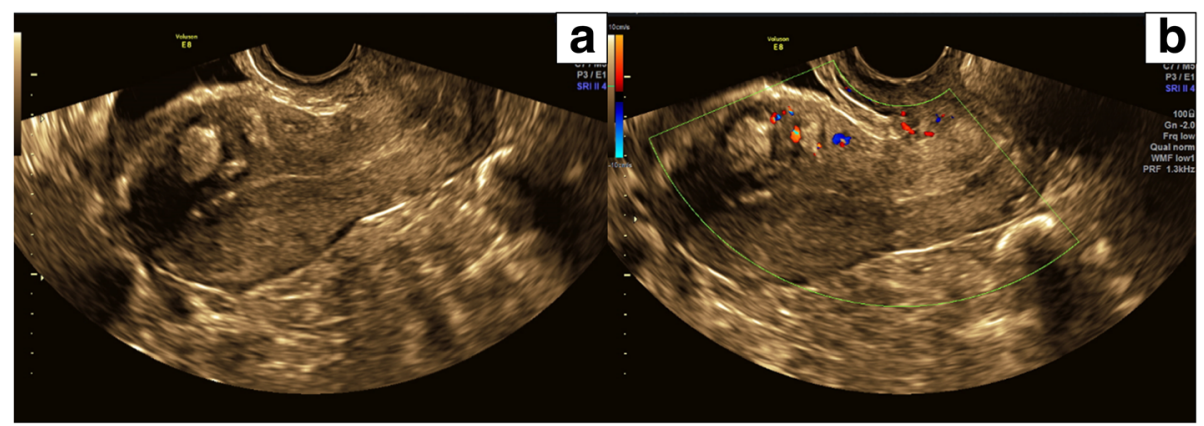

Fig. 3 a Sagittal transvaginal pelvic ultrasound image 2 weeks post UAE demonstrating echogenic PHIL embolic material in the anterior myometrium at the site of the treated AVM $\mathbf{b}$ Colour Doppler overlay demonstrating markedly reduced vascularity

AVMs with lower morbidity and mortality, over the surgical alternatives of vessel ligation or hysterectomy (Ghai et al., 2003; Peitsidis et al., 2011; Touhami et al., 2014). Advantages of embolization include prompt and accurate identification of bleeding site, preservation of uterus and subsequent fertility as well as reduced recurrence of bleeding from collaterals due to ability to perform more distal occlusion of the nidus. However despite its widespread use, a recent systematic review concluded that only low-level evidence supported the role of embolization and in light of the heterogeneity of pathology, embolic agents and approaches, it emphasized the importance of refining the procedural protocol (Yoon et al., 2016).

Regardless of its location, the goal of AVM embolization is complete obliteration of the nidus, while avoiding unwanted non-target reflux into the feeding arteries or premature embolization of its draining veins. In situations where tissue or end-organ death is a desired end point, permanent embolic agents and smaller particles are the preferred choice (Koçer et al., 2016a). Vascular abnormalities, including AVMs, can be successfully treated by permanent occlusion as the host organ can remain well supplied by collaterals (Lubarsky et al., 2010).

PHIL, a novel liquid embolic agent, is a ready-to-use non-adhesive copolymer. It is dissolved in dimethyl sulfoxide (DMSO), and does not require any preparation and is covalently bound to its iodine component, which provides its inherent radiopacity (Vollherbst et al., 2017). PHIL liquid embolic system consists of a sterile, prefilled $1.0 \mathrm{~mL}$ syringe of the liquid embolic agent, a sterile, prefilled $1.0 \mathrm{~mL}$ syringe of DMSO, and microcatheter hub adaptors. A DMSO-compatible delivery microcatheter that is indicated for use in the neurovascular or peripheral vasculature is used to access the target for embolization. PHIL is delivered by slow, controlled injection under fluoroscopic control. The DMSO solvent dissipates into the blood, causing the copolymer to precipitate forming an embolus. PHIL polymerizes from the outside to the inside, while penetrating distally in the vascular lesion. Final solidification of the injected agent occurs within $5 \mathrm{~min}$ according to the manufacturer (Leyon et al., 2016).

The non-adhesive nature of this agent affords potential for longer injection times as well as the capacity to perform control angiography mid-procedure. Its preference as an embolic agent in the management of cerebral AVMs and dural arteriovenous fistulae is increasing (Koçer et al., 2016a; Samaniego et al., 2016; Lamin et al., 2017).

The use of other liquid embolics, for example N-butyl cyanoacrylate (NBCA) and ethylene vinyl alcohol copolymer (Onyx), in the management of uterine AVMs has been reported previously with favourable clinical results. Compared to Onyx, shorter intervals (30-60 s) are required during injection of PHIL ( $2 \mathrm{~min}$ in the case of Onyx), which allows a greater margin for reflux $(2 \mathrm{~cm})$. There is less streak artefact with PHIL compared to Onyx on follow-up CT imaging. The PHIL agent does not contain micronized tantalum unlike Onyx; therefore, PHIL is more homogenous and does not require prior agitation prior to use (Hemingway, 1984). The radiation dose is perhaps smaller for the patient and the operator in case of PHIL due to a quicker injection time and the ability to change the radiation factors for visualization during the procedure (Hemingway, 1984), which is of added value for pelvic angiographic procedures in young females. However, PHIL has limited visibility during passage through the microcatheter (especially PHIL 25\%). After passage through the tip of microcatheter, the visibility of PHIL is lower than Onyx (Koçer et al., 2016a).

Gel foam is a biological substance prepared from purified skin gelatin. Related studies mostly support preservation of menstrual function and fertility following uterine embolization with gel foam, with one study reporting resumption of menses in all of their patients. Another study reported $98 \%$ preservation of menses and $82 \%$ successful future pregnancies (Touhami et al., 2014; Farouk et al., 2016; Cheng et al., 2017). 
Despite literature supporting preservation of fertility, gel foam poses some inherent disadvantages as an embolic agent for uterine AVM embolization compared to newer agents. As a temporary embolic agent, recanalization can occur in the weeks following embolisation (Lubarsky et al., 2009). The smaller size of the particles in gel foam powder preparation, also results in increased risk of potential and unwanted ischemia from non-target reflux (Siskin et al., 2000).

Our patient did not experience any post-embolisation complication, including major pain, infection and post-embolisation syndrome (PES). PES is the most common complication following UAE for uterine AVMs (Hughes \& Reidy, 2003). One study looking at a large variation in indication for embolisation, both in location and pathology, demonstrated a lower incidence in PES when treatment was for acute bleeding (Hemingway, 1984). It was inferred that this was in relation to decreased volume in of necrotic tissue or thrombosed vasculature, as point of occlusion is as directed as possible (Hemingway, 1984). A case series demonstrated that, unlike its counterpart liquid embolic agent Onyx, PHIL causes moderate vascular inflammatory effect but no angionecrosis (Koçer et al., 2016b). This might be related to possible reduced PES rate after PHIL.

\section{Conclusion}

In conclusion, we report a case of successful endovascular treatment of a uterine AVM with the novel liquid embolic agent PHIL. Further studies are needed to establish possible superiority and fertility preservation over other embolic agents such as Onyx.

\section{Abbreviations}

AVM: Arterio venous malformation; PHIL: Precipitating hydrophobic injectable liquid; UAE: Uterine artery embolization

\section{Acknowledgements}

No acknowledgment to make.

\section{Funding}

No funding has been obtained for this project.

\section{Availability of data and materials}

Available.

\section{Authors' contributions}

DK, writing up the manuscript and overseeing the project. GG: writing up the manuscript. JM and HKK: reviewing the manuscript and making changes. SL: reviewing the manuscript and overseeing the whole project. All authors read and approved the final manuscript.

\section{Ethics approval and consent to participate}

Institutional ethics approval obtained.

\section{Consent for publication}

Consent is available.

\section{Competing interests}

The authors declare that they have no competing interests.

\section{Publisher's Note}

Springer Nature remains neutral with regard to jurisdictional claims in published maps and institutional affiliations.

\section{Author details}

${ }^{1}$ Interventional Radiology, The Canberra Hospital, Canberra, Australia.

${ }^{2}$ Interventional Radiology, Austin Health, Melbourne, VIC, Australia. ${ }^{3}$ School of Medicine, Deakin University, Waurn Ponds, Geelong, Australia. ${ }^{4}$ Interventional Radiology, Northern Health, Melbourne, VIC, Australia.

Received: 18 February 2019 Accepted: 29 April 2019

Published online: 17 May 2019

\section{References}

Cheng HH, Tsang LL, Hsu TY, Kung CT, Ou CY, Chang CD et al (2017) Transcatheter arterial embolization as first-line rescue in intractable primary postpartum hemorrhage: assessment, outcome, and subsequent fertility. J Formos Med Assoc 116(5):380-387 Available from: https://doi.org/10.1016/j. jfma.2016.06.011

Farouk O, Elbasuony W, Elbohouty A (2016) Uterine artery embolization versus surgical management in primary atonic postpartum hemorrhage: a randomized clinical trial. Egypt J Radiol Nucl Med 47(3):817-823 Available from: https://doi.org/10.1016/j.ejrnm.2016.06.012

Ghai S, Rajan DK, Asch MR, Muradali D, Simons ME, TerBrugge KG. Efficacy of embolization in traumatic uterine vascular malformations. J Vasc Interv Radiol. 2003 [cited 2018 Dec 13];14(11):1401-1408. Available from: https:// www.sciencedirect.com/science/article/pii/S1051044307602863

Hemingway P (1984) Complicanze Embolizzazioni Epatiche, pp 669-672

Hughes JL, Reidy JF. Imaging and treatment of uterine fibroids including the role of uterine artery embolisation. Imaging. 2003 [cited 2019 Jan 10];15(2):79-88. Available from: http://www.birpublications.org/doi/10.1259/img.15.2.150079

Kasznica J, Nisar N (1995) Congenital vascular malformation of the uterus in a stillborn: a case report. Hum Pathol 26(2):240-241. Available from: https:// www.ncbi.nlm.nih.gov/pubmed/7860055

Koçer, N., Hanımoğlu, H., Batur, Ş., Kandemirli, S. G., Kızılkılıç, O., Sanus, Z., ... Kaynar, M. Y. (2016a). Preliminary experience with precipitating hydrophobic injectable liquid in brain arteriovenous malformations. Diagn Interv Radiol https://doi.org/10.5152/dir.2015.15283

Koçer N, Hanımoğlu H, Batur Ş, Kandemirli SG, Kızılkılıç O, Sanus Z et al (2016b) Preliminary experience with precipitating hydrophobic injectable liquid in brain arteriovenous malformations. Diagnostic Interv Radiol 22(2):184-189

Kwon JH, Kim GS (2002) Obstetric iatrogenic arterial injuries of the uterus: diagnosis with US and treatment with transcatheter arterial embolization. Radiographics [Internet] 22(1):35-46 Available from: http://eutils.ncbi.nlm.nih. gov/entrez/eutils/elink.fcgi?dbfrom=pubmed\&id=11796896\&retmode= ref\&cmd=prlinks\%5Cnpapers2://publication/uuid/D6DF3AFE-1489-491C-9F81ABBE27F1EE20

Lamin S, Chew HS, Chavda S, Thomas A, Piano M, Quilici L, et al. Embolization of intracranial dural arteriovenous fistulas using PHIL liquid embolic agent in 26 patients: A multicenter study. Am J Neuroradiol. 2017;38(1):127-131. Available from: http://www.embase.com/search/results?subaction=viewrecord\&from= export\&id=L614086364\%5Cnhttp://dx.doi.org/10.3174/ajnr. A5037\%5Cnhttp:// vb3lk7eb4t.search.serialssolutions.com?sid=EMBASE\&issn=1936959x\&id=doi: 10.3174\%2Fajnr.A5037\&atitle=Embolization+of+intrac

Leyon JJ, Chavda S, Thomas A, Lamin S (2016) Preliminary experience with the liquid embolic material agent PHIL (precipitating hydrophobic injectable liquid) in treating cranial and spinal dural arteriovenous fistulas: technical note. J Neurolnterventional Surg https://doi.org/10.1136/neurintsurg-2015011684

Lubarsky M, Ray C, Funaki B (2010) Embolization agents-which one should be used when? Part 2: small-vessel embolization. Semin Intervent Radiol 27(1): 99-104

Lubarsky M, Ray CE, Funaki B (2009) Embolization agents-which one should be used when? Part 1: large-vessel embolization. Semin Intervent Radiol. 26(4): 352-357

Molvi SN, Dash K, Rastogi H, Khanna SB. Transcatheter embolization of uterine arteriovenous malformation: report of 2 cases and review of literature. J Minim Invasive Gynecol. 2011 Nov 1 [cited 2019 Jan 21];18(6):812-819. Available from: https://www.sciencedirect.com/science/article/pii/ S1553465011003712 
Peitsidis P, Manolakos E, Tsekoura V, Kreienberg R, Schwentner L (2011) Uterine arteriovenous malformations induced after diagnostic curettage: a systematic review. Arch Gynecol Obstet 284(5):1137 Available from: https://doi.org/10. 1007/s00404-011-2067-7

Samaniego EA, Kalousek V, Abdo G, Ortega-Gutierrez S (2016) Preliminary experience with precipitating hydrophobic injectable liquid (PHIL) in treating cerebral AVMs. J Neurointerv Surg 8(12):1253-1255

Sellers F, Palacious-Marques A, Moliner B, Bernabeu R (2013) Uterine arteriovenous malformation. Br Med J 16(1):41-44

Siskin GP, Englander M, Stainken BF, Ahn J, Dowling K, Dolen EG (2000) Embolic agents used for uterine fibroid embolization. Am J Roentgenol 175(3):767-773

Timor-Tritsch IE, Haynes MC, Monteagudo A, Khatib N, Kovács S (2016) Ultrasound diagnosis and management of acquired uterine enhanced myometrial vascularity/arteriovenous malformations. Am J Obstet Gynecol 214(6):731.e1731.e10 Available from: https://doi.org/10.1016/j.ajog.2015.12.024

Touhami O, Gregoire J, Noel P, Trinh XB, Plante M (2014) Uterine arteriovenous malformations following gestational trophoblastic neoplasia: a systematic review. Eur J Obstet Gynecol Reprod Biol 181:54-59 Available from: https:// doi.org/10.1016/j.ejogrb.2014.07.023

Vollherbst DF, Sommer CM, Ulfert C, Pfaff J, Bendszus M, Möhlenbruch MA (2017) Liquid embolic agents for endovascular embolization: evaluation of an established (Onyx) and a novel (PHIL) embolic agent in an in vitro AVM model. Am J Neuroradiol 38(7):1377-1382

Yoon DJ, Jones M, Al TJ, Buhimschi C, Dowell JD (2016) A systematic review of acquired uterine arteriovenous malformations: pathophysiology, diagnosis, and Transcatheter treatment. Am J Perinatol Rep 6:6-14

\section{Submit your manuscript to a SpringerOpen ${ }^{\circ}$ journal and benefit from:}

- Convenient online submission

- Rigorous peer review

- Open access: articles freely available online

- High visibility within the field

- Retaining the copyright to your article

Submit your next manuscript at $\boldsymbol{\nabla}$ springeropen.com 